\title{
Seroprevalence of infectious bursal disease in chickens managed under backyard production system in Central Oromia, Ethiopia
}

\author{
Tesfaheywet Zeryehun ${ }^{1 *}$ and Getnet Fekadu ${ }^{2}$ \\ ${ }^{1}$ Department of Parasitology and Pathology, College of Veterinary Medicine, Haramaya University, \\ P.O.Box 301, Dire Dawa Ethiopia. \\ ${ }^{2}$ Department of Biomedical Science, College of Veterinary Medicine, Haramaya University, \\ P.O.Box 138, Dire Dawa Ethiopia.
}

Accepted 5 September, 2012

\begin{abstract}
Cross-sectional study was conducted from November, 2009 to May, 2010 to determine the seroprevalence of infectious bursal disease (IBD) in backyard chickens and to identify the likely potential risk factors in selected sites in Central Oromia, Ethiopia. The study methods involved collection of serum samples, questionnaire surveys, and serological task conducted in laboratories. Accordingly, a total of 276 local backyard chickens were sampled. The sampling involved all chickens at different age groups of both sexes and with no history of previous vaccination against IBD. The samples were processed by using ProFLOK ${ }^{\circledR}$ PLUS indirect enzyme-linked immunosorbent assay (ELISA) kits. Out of 276 serum samples tested, 227 were positive for indirect ELISA technique and the overall prevalence of IBD in the study area was found to be $82.2 \%(227 / 276)$. The prevalence of IBD was significantly influenced by site $\left(X^{2}=44.353, P=0.000\right)$. However, no significant difference was observed between age groups $\left(X^{2}=0.535, P=0.464\right)$ and sex $\left(X^{2}=0.25, P=0.870\right)$. The questionnaire also revealed that all the chickens raised in the household were non-vaccinated (100\%), majority of them $(70 \%)$ used own source of replacement chickens and $60 \%$ of the house hold poultry producers have no information about the disease. Furthermore, $70 \%$ of the farmers did not use disinfectants. Therefore, it can be concluded that IBD have high prevalence in Central Oromia, Ethiopia, and serious attention is warranted.
\end{abstract}

Key words: Seroprevalence, infectious bursal disease (IBD), indirect enzyme-linked immunosorbent assay (ELISA), backyard chickens, Central Oromia Ethiopia.

\section{INTRODUCTION}

Chicken production under backyard system has long been an important component of rural economy in Ethiopia. Rural poultry constitutes about $99 \%$ of the national poultry production of Ethiopia (Alamargot, 1987). Village chickens have been widely used for cheap source of protein through their main output, egg and meat production (Alemu, 1995; Tadelle and Ogle, 2001; Halima

*Corresponding author. E-mail: tesfahiwotzerihun@yahoo.com. et al., 2007). However, unlike the intensive one, traditional poultry production system is characterized by low input, low output and periodic destruction of a large portion of the flock due to outbreak of disease. Like all other animals, backyard poultry too suffer from a wide range of maladies. In the village poultry production systems, disease was cited as the most important stumbling block for production problem in Ethiopia (Alemu, 1995; Tadelle and Ogle, 2001; Lobago et al., 2003). Nowadays as part of the intensification of poultry production strategies, introduction of diseases of various 
etiologies into several poultry farms concurrent with importation of exotic breeds to backyard chickens is becoming a growing concern. In line with distribution of exotic breeds to farmers, it is creating a great treat to the indigenous backyard chickens (Alamargot, 1987; Zeleke et al., 2005a). Among others, Newcastle diseases, Marek's disease, and infectious bursal disease (IBD) are the most important viral diseases inflicting heavy losses (Alamargot, 1987; Duguma et al., 2005; Zeleke et al., 2005a, b; Mazengia et al., 2009). Currently from those cited viral disease, IBD is the most important threat to poultry production in the country (Zeleke et al., 2005b; Solomon and Abebe, 2007).

IBD is a highly contagious, acute viral disease of poultry caused by IBD virus (IBDV). IBD is caused by the genus Avibirna virus of the family Birnaviridae (Van den berg, 2000). IBD is very pathogenic to chicks, although it may affect other avian species. Only young birds are clinically affected. Severe acute disease of 3 to 6 weeks old birds is associated with high mortality, but a less acute or sub clinical disease is common in 0 to 3 weeks old birds. The disease imposes threat through mortality, reduced weight gain, and condemnation of carcasses due to marked hemorrhage in the skeletal muscle (Van den berg, 2000; Tesfaheywet et al., 2012) and secondary losses due to immunosuppression (Lukert and Saif, 1997).

Currently, IBDV has a worldwide distribution, occurring in all major poultry producing areas. During the 63rd general session of the Office International des Epizooties (OIE, Paris, 15 to 19 May, 1995), it was estimated that IBD has considerable socio-economic importance at the international level, as the disease is present in more than $95 \%$ of the member countries (Eterradossi, 1995). The report of introduction and existence of IBD in Ethiopia has recently come with the report of IBD outbreak in Debre Zeit large scale poultry farms in 20 to 45 days old broiler and layer chickens and indicated that the mortality rate of the disease ranges from 45 to $50 \%$; however, an overall of 49.83 and $93.30 \%$ was recorded for mortality rate and seroprevalence of IBD antibody, respectively (Zeleke et al., 2005b). Solomon and Abebe (2007) have also reported $98.9 \%$ seropositivity at Andasa Poultry Farm. Case report study at Bahir Dar and Farta areas indicated an incidence rate of 29.40 and $21.70 \%$ in backyard chickens in an outbreak in Debre Zeit (Zeleke et al., 2005b; Mazengia et al., 2009).

Although, in Ethiopia, IBD is one of the important viral disease prevalent in the back yard poultry production system, but despite its importance in the country the status of the disease (prevalence, risk factors and distribution) is not well documented since there has been very limited researches done so far in the backyard poultry production system. Therefore, the objectives of this study were to determine the seroprevalence of IBD in backyard chickens and to investigate the host risk factors associated with the disease in Central Oromia, Ethiopia.

\section{MATERIALS AND METHODS}

\section{Study area}

The study was carried out from November, 2009 to May, 2010 in Peasant Association and Kebelles of Debre Zeit. Debre Zeit is located at $9^{\circ} \mathrm{N}$ and $40^{\circ}$ East, $47 \mathrm{~km}$ Southeast of Addis Ababa. Debre Zeit is the center of Ada'a Liban district (Woreda), and the district has a total land area of about $1610.56 \mathrm{~km}^{2}$ and is divided into three agro-ecological zones, namely, mid land (94\%), high land $(3 \%)$, and low land (3\%) (Government of Oromia Region, 2006). The altitude is about 1850 m.a.s.l. It is an important town where most governmental institutions, national, and international research centers and commercial poultry farms are located. Debre Zeit experiences a bimodal pattern of rainfall with the main rainy season extending from June to September (of which $84 \%$ of rain is expected) and short rainy seasons from March to May with an average annual rain fall of $800 \mathrm{~mm}$. The mean annual minimum and maximum temperatures are 12 and $27^{\circ} \mathrm{C}$, respectively with an overall average of $18.7^{\circ} \mathrm{C}$. Highest temperatures are reached in May and the mean relative humidity is $61.3 \%$ (NMSA, 2003).

\section{Study population}

The study animals were backyard chickens (unvaccinated) found in different Kebelles and Peasant Association of Debre Zeit. The chickens were categorized in to two age groups $(<3$ weeks and $\geq 3$ weeks), this category of age groups were made based on the development of the bursa of Fabricius, hence, producing difference on the susceptibility of the age groups to IBD (De Hedt et al., 2005). And the study chickens were also categorized into two sex groups (male and female). None of the sampled chickens were vaccinated against IBD. The assessment of vaccination status of the selected chickens to be sampled was made by performing thorough questionnaire survey for each and every household.

\section{Study design}

\section{Study methodology}

Cross sectional study was applied from November, 2009 to May, 2010 to determine the seroprevalence of IBD in unvaccinated backyard chickens and to describe the seroprevalence as well as distribution of the disease in the Debre Zeit town. Blood samples were collected from chickens that were selected randomly from study area. Age, sex, and blood sample collection sites were considered as important risk factors for the disease. A simple random sampling technique was applied to select the sampling units, $21.7 \%$ expected prevalence was taken to determine samples size that should be selected with 95\% confidence interval $(\mathrm{Cl})$ and $5 \%$ desired absolute precision $(d=0.05)$. The sample size was determined according to Thrustfield (1995).

$\mathrm{n}=\frac{1.96^{2} \times \operatorname{Pexp}(1-\mathrm{Pexp})}{\mathrm{d}^{2}}$

where $\mathrm{n}$ is the required sample size, Pexp is the expected prevalence, and $d$ is the desired absolute precision, for $n=259$.

The total sample size was proportionally allocated between two areas (Kebelles and Peasant Association found in Debre Zeit). To avoid loss of sample units and increase precision, additional samples were collected. A total sample of 276 was collected from selected households found in the Kebelles and Peasant Association of the town (that is, 17 additional blood samples were collected). 


\section{Collection of blood samples}

Sterile $3 \mathrm{ml}$ disposable syringes with needle size 21 gauge and 11/2" were used to collect blood samples from brachial (wing) vein of the chickens. The whole blood collected from local chickens was labeled and allowed to clot under normal atmospheric temperature in the slant position within the syringe for $24 \mathrm{~h}$. Then, the clear serum was harvested in to labeled cryo vials and was stored at $20^{\circ} \mathrm{C}$ until the ELISA test was carried out.

\section{Indirect ELISA}

The serum samples were then processed and were tested at the National Veterinary Institute (NVI). The procedure employed in the laboratory was an Indirect ELISA using commercial ELISA infectious bursal disease virus antibody test kit.

\section{ELISA validity test}

The IBD ELISA titer values obtained represent a comparison of the IBD antibody level within each field chicken serum and the IBD ELISA kit positive and non reactive sera. Therefore, it is important to first determine that the IBD ELISA positive and normal control sera values obtained are valid or not. Accordingly, optical density (OD) values of negative control $<0.25$ is considered invalid IBD ELISA and that of corrected positive control serum value ranges between 0.25 and 0.9 . If $O D$ is out of these ranges, IBD ELISA result is considered invalid.

\section{Interpretation of ELISA test}

To interpret the ELISA test result, serum sample positive control (SP) ratio was required. If $S P$ value was $\geq 0.05$ it represents a chicken serum which contains a significant ELISA detectable IBD antibody level as compared to the IBD ELISA kit positive and normal control sera, but $\mathrm{SP}<0.5$ indicates a negative result.

\section{Data analysis}

The data collected and results for the seroprevalence were analyzed statistically using statistical packages for social sciences (SPSS) 17.0 software program. The association between seroprevalence rate and explanatory factors (age, sex, and locality) was carried out by way of chi-square $\left(\chi^{2}\right)$ test. Significant difference was held at P-values less than 0.05 in all analysis.

\section{RESULTS}

\section{Seroprevalence by sites}

A total of 276 serum samples were collected from backyard chickens and tested by using indirect ELISA and an overall prevalence of $82.2 \%(227 / 276)$ IBD was recorded in the study area.

From the thirteen sites investigated in this study, 7 were Peasant Associations and the remaining 6 were Kebelles. High difference in the prevalence of IBD was observed in the thirteen sites of the study area, accordingly; Kajjima, Qurqura Babogaya, Denbi, Hedhii, Arenguade Bahir, Kalliti, Kebelle 3, Kebelle 9, Kebelle 5,
Kebelle 2, Kebelle 7, and Kebelle 1, with a prevalence of 91.7 (33/36), 90.0, 95.0, 86.7, 85.0, 35.3, 53.3, 80.0, $80.0,70.0,86.7,87.0$, and $53.3 \%$, respectively. Moreover, significant difference was also observed among the sites $\left(\chi^{2}=44.353, P=0.000\right)$ (Table 1$)$.

\section{Sex-wise seroprevalence}

Both sexes of backyard chickens were compared and a prevalence rate of $81.9 \%(113 / 138)$ from females and $82.6(114 / 138)$ from males were found. The prevalence of IBD at the study area was also found to be statistically not significant $\left(\chi^{2}=0.25, P=0.875\right)$ between sex groups (Table 2).

\section{Age-wise seroprevalence}

In this study, the highest prevalence of IBD was recorded in age groups of greater than three weeks (83.9 $(115 / 137))$ than less than three weeks $(80.6 \%(112 / 139))$. In addition, seroprevalence of IBD in the Peasant Associations and Kebelles are statistically not significant $\left(\chi^{2}=0.535, P=0.464\right)$ between the two age groups (Table 3).

\section{DISCUSSION}

The present study conducted on backyard chickens in both Peasant Associations and Kebelles of Debre Zeit revealed the presence of IBDV specific anti body in the absence of vaccination, which indicate the presence of field exposure of household chickens to the virus. According to this study, the overall seroprevalence of IBD in the study area (Debre Zeit) was relatively high $(82.20 \%)$ and it was in agreement with various serological studies conducted in different countries of the world. The report of Zeleke et al. (2005b) and Woldemariam and Wossene (2007) indicated high seroprevalence rate of IBD that was 93.3 and $100 \%$, respectively. Mazengia (2008) reported an overall prevalence of $51.10 \%$ from Bahir Dar and Farta districts and Nigussie (2007) reported a high seroprevalence of $61 \%$ in backyard chickens of Addis Ababa and Adami Tulu areas which were also in agreement with current study. Result of serological survey can vary depending on the sensitivity and specificity of the diagnostic tool applied. The indirect ELISA kit used in this study was shown to be highly sensitive and specific. Generally, ELISA test is considered as an ideal serological test in the diagnostic virology all over the world due to its specificity, sensitivity, simplicity and minimum time requirement (Beared, 1989).

Other researchers also reported high seroprevalence of IBD which is more or less similar with this study. Abrar (2007) reported high seroprevalence rate of IBD (76.3\%) 
Table 1. The association of IBD with site.

\begin{tabular}{lccc}
\hline Site & Total & Positive (\%) & $\chi^{2}$ (P-value) \\
\hline PAs & & & \\
Kajjima & 36 & $33(91.7)$ & \\
Qurqura & 30 & $27(90.0)$ & \\
Babogaya & 40 & $38(95.0)$ & \\
Denbi & 15 & $13(86.7)$ & \\
Hedhii & 20 & $17(85)$ & \\
Arenguade Bahir & 17 & $6(35.3)$ & \\
Kalliti & 15 & $8(53.3)$ & $44.353(0.000)$ \\
& & & \\
Kebelles & & & \\
Kebelle 3 & 10 & $8(80.0)$ & \\
Kebelle 9 & 10 & $8(80.0)$ & \\
Kebelle 5 & 10 & $7(70.0)$ \\
Kebelle 2 & 30 & $26(86.7)$ & \\
Kebelle 7 & 23 & $20(87.0)$ \\
Kebelle 1 & 20 & $8(40.0)$ & \\
\hline
\end{tabular}

Table 2. Association of IBD with sex.

\begin{tabular}{lccc}
\hline Sex & Total number examined & Number of positive (\%) & $\chi^{2}$ (P-value) \\
\hline Female & 138 & $113(81.9)$ & $0.25(0.870)$ \\
Male & 138 & $114(82.6)$ & \\
\hline
\end{tabular}

Table 3. Association of IBD with age.

\begin{tabular}{lccc}
\hline Age & Total number examined & Number of positive (\%) & $\chi^{2}$ (P-value) \\
\hline$<3$ weeks & 139 & $112(80.6)$ & $0.535(0.464)$ \\
$\geq 3$ weeks & 137 & $115(83.9)$ & \\
\hline
\end{tabular}

from Ethiopia. Ibrahim and Tanya (2001) from Nigeria, Kelly et al. (1994) from Zimbabwe reported a seroprevalence of IBD 60.6 and $55 \%$, respectively. All the aforementioned results strongly agree with the current study and they also indicate that, nowadays IBD is not the problem of intensive production only, but it is also the newly emerged problem for the household chicken farmers too.

In contrary to this study, some researchers also reported lower seroprevalence rate of IBD from different countries. Tesfaye (2008) reported a seroprevalence rate of $29 \%$ by using agar gel immune diffusion (AGID) test as diagnostic tool. Similarly, Ndanyi (2004) from Kenya also reported a seroprevalence rate of $49.3 \%$ by using AGID as diagnostic tool. Moreover, Tsai and Lu (1993) and Singh et al. (1994) also indicated a seroprevalence rate of 45 and $46.2 \%$, respectively. This difference might be due to less sensitivity of AGID as compared to ELISA kit used by the current study. The aforementioned suggestion is with agreement to the Manual of Office International des Epizooties (OIE, 2004), that described ELISA as the most ideal, sensitive and specific diagnostic tool used for serological diagnosis of viral antibodies. In addition to this, the backyard chickens in the current study were poorly managed (free scavenging) in which once IBD occurs, it is inevitable to be transmitted to the house hold chickens found nearby, because in the town (Debre Zeit) most house hold chickens are free to search seed together with neighboring chickens in the village (so transmission from one flock to the other flock is common). The other reason may be cross contamination from exotic breed chickens, because it is common in the town to purchase exotic breed of chickens and raise them with local chickens for the purpose of production of egg (so transmission from intensive farms to backyard farming system occurs). IBD is common in the exotic 
breed chickens; this is in accordance with the study of Zeleke et al. (2005b).

Among the sampled Peasant Associations and Kebelles of Debre Zeit, the highest seroprevalence was found in Babogaya (95.0\%), Kajjima (91.7\%) and Qurqura (90.0\%), which are all under the Peasant Association of the town. This may be due to the poor management of the backyard chickens and high contact to the stressful external environment (hence, promoting transmission of IBD from diseased flocks to healthy flocks) as compared to the other Kebelles and Peasant Associations observed having low seroprevalence in Arenguade Bahir (35.5\%) and less extent Kalliti (53.3\%).

Although, variation in seroprevalence was seen across sex groups, but the result was not statistically significant. This could be due to the exposure of male and female chickens to common source of infection including fecal contaminated feed during scavenging of seed or transmission of IBDV from newly purchased exotic chickens to local backyard chickens, because the disease is prevalent in exotic breed chickens, exotic chickens are more susceptible than local chickens, this is supported by Zeleke et al. (2005b).

The difference in seroprevalence was seen across the age groups ( 0 to 3 weeks and $\geq 3$ weeks), the seroprevalence for the chicken less than 3 weeks and $\geq 3$ weeks were 80.6 and $83.9 \%$, respectively, this variation might be due to the difference in the development of bursa of Fabricius, which is mature and maximum size reached at age of 3 to 6 weeks. This is supported by the result of Saif et al. (2000) who reported that chickens of age 3 to 6 weeks were more susceptible to IBD because the bursa, the site for IBDV multiplication, is matured and maximum in size at this age.

In general, this study revealed a high seroprevalence, this might be due to frequent exposure of local backyard chickens to immunosuppression causing factors such as heat stress during scavenging seeds, water deprivation, and poor nutrition (like hypoproteinemia), which leads to production of steroids which result in suppression of the immunity system. Hypoproteinemia also decrease immunity, because of insufficient protein which are major precursor of immunity system (Hassan et al., 1998).

This study confirmed that IBD is prevalent among backyard chicks in Debre Zeit (district), which suggests field exposure to IBDV since there was no vaccination against IBD in the sampled backyard chickens. The finding also suggests that village chickens might be exposed to IBDV earlier in life, because the virus is constantly circulating in the environment. As a result, the clinical form of IBD probably is the commonest form that occurs among these birds. It is also likely for chicks to be protected by maternal antibodies early in their life, but exposed to clinical disease and mortality later when the maternal antibody declines. Among the risk factors studied (sex, age and study area/site), study area (site of blood sample collection) was found to be highly correlated to the occurrence of IBD in the study area.
Therefore, management practices such as disease monitory program, appropriate prevention and control measure should be implemented. Additionally, extensive extension service must be launched to create awareness among the farmers about the disease. Most importantly, routine survey should be conducted to assess the degree of IBD distribution and be able to identify the IBD virus strain circulating in the study area

\section{REFERENCES}

Alamargot $J$ (1987). Avian pathology of industrial farms in Ethiopia. Institute of Agricultural Research (IAR) Proceeding $1^{\text {st }}$ National live stock improvement conference, Addis Ababa, Ethiopia pp.114-117.

Alemu $Y$ (1995). Poultry production in Ethiopia. World Poult. Sci. J. 51:197-201.

Duguma R, Yami A, Dana N, Hassen F, Esatu W (2005). Marek's disease in local chicken strains of Ethiopia reared under confined management regime in central Ethiopia. Revue Méd. Vét. 156(11):541-546

Eterradossi N (1995). Progress in the Diagnosis and Prophylaxis of Infectious Bursal Disease in Poultry. Comprehensive reports on technical items presented to the International Committee or to regional Commissions, $63^{\text {rd }}$ General Session of the Office International des Epizooties (OIE), 15 to 19 May 1995, OIE, Paris pp. $75-82$.

Government of Oromia Region (2006). Socio-economic profile of East Shewa Zone (Last accessed August 1, 2006) http://orimiagov.org.

Hassan SK, Ahmed F, Siddique N (1998). A study on the Infectious bursal disease around Rausalpind/Islamabad. Pak. Int. Live. Res. pp.8:84-88.

Ibrahim UI, Tanya SN (2001). Prevalence of Antibodies to Infectious Bursal Disease (IBD) in Village Chickens in Sahel Zone of Nigeria. Bull. Anim. Health Prod. 49:150-152.

Kelly PJ, Daniel C, Christopher R, John R, Aggrey M, Frans D, Peter RM (1994). Diseases and management of back yard chicken flock in Chitungwiza, Zimbabwe. Avian Dis. 38:626-629.

Lobago F, Nigussie D, Wossene A, Ashenafi H (2003). Study on major disease of chickens in Debre Zeit, Central Ethiopia. Bull. Anim. Health Prod. Afr. 51:11-21.

Lukert PD, Saif YM (1997). Infectious boreal disease. In: Diseases of poultry, Tenth Edition, Calnek BW, ed. IOWA state university press, Ames, IOWA, USA, pp.721- 738.

Mazengia H (2008). Newcastle disease and Infectious Bursal Disease in chickens among households of Bahir Dar and Farta districts, Northwest Ethiopia, DVM Thesis, FVM, AAU, Ethiopia.

Mazengia H, Tilahun SB, Negash T (2009). Incidence of infectious bursal disease in village chickens in two districts of Amhara Region, Northwest Ethiopia. J. Livest. Res. Rural Dev. 21:12.

Ndanyi MR (2004). A study to determine causes of mortality and the effect of infectious bursal disease (IBD) vaccination in village chickens in Taita Taveta district of Kenya. MSc. Thesis, Department of Veterinary Microbiology and Network of Smallholder poultry Development, the royal Veterinary and Agriculture University, Frederiksberg, Denmark.

NMSA (2003). National Metrology Service Agency: Rain fall, humidity and temperature data. Addis Ababa, Ethiopia.

OIE (2004). Chapter 2.7.1: Infectious bursal disease (Gumboro Disease).In: manual of diagnostic tests and vaccines for terrestrial animals, $5^{\text {th }}$ ed. Updated: http:// WWW.oie.int /eng/OIE/ Organization/ en LR.htm.

Saif EM, Ally A, Ajit E, Mohamed FM (2000). Epidemiological Studies on Gumboro disease in Upper Egypt. Assuit Vet Med. J. 42:223-241.

Tadelle D, Ogle B (2001). Village poultry production systems in the central highlands of Ethiopia. Trop. Anim. Health Prod. 33:521-537

Tesfaye R (2008). Seroprevalence of infectious bursal disease in nonvaccinated backyard local chickens of East Showa zone, Akaki, Debrezeit and Adama. DVM Thesis, FVM, AAU, Ethiopia.

Tesfaheywet Z, Hair-Bejo M, Rasedee A (2012). Hemorrhagic and 
Clotting Abnormalities in infectious bursal disease in specificpathogen-free chicks. World Appl. Sci. J. 16(8):1123-1130.

Thrustfield M (1995). Veterinary epidemiology. $2^{\text {nd }}$ ed. Black well science Ltd., Oxford, London.

Tsai HJ, Lu YS (1993). Epidemiology of infectious bursal disease in Taiwan in 1992. J. Chinese Soc. Vet. Sci. 19:249-258.

Van den berg TP (2000). Acute infectious bursal disease in poultry: A review. Avian Pathol. 29:175-194.

Woldemariam S, Wossene A (2007). Infectious bursal disease (Gumboro Disease): Case report at Andasa poultry farm, Amhara region. Ethiop. Vet. J. 11:141-150.
Zeleke A, Sori T, Gelaye E, Ayelet G (2005a). Newcastle disease in village chickens in the southern and rift valleydistricts in Ethiopia. Int. J. Poult. Sci. 7:508-510.

Zeleke A, Gelaye E, Sori T, Ayelet G, Sirak A, Zekarias B (2005b). Investigation on Infectious Bursal Disease outbreak in Debre Zeit, Ethiopia. Int. J. Poult. Sci. 7:504-506. 